\title{
Antifungal Activity of Lemongrass Oil Against Pathogenic Fungi
}

\author{
Yashwanth Gangavarapu, Suhas Palwai \\ Adlai E Stevenson High School, 1 Stevenson Dr, Lincolnshire, Illinois, 60061, USA; gangavarapuyash@gmail.com
}

ABSTRACT: Plant pathogenic fungi cause diseases in plants and have a devastating impact on the global food security within our ever-growing population. The damage to crops not only results in low crop yields but also leaves millions of people starving due to food shortages. Various essential oils have been tested for antifungal activity in vitro and in vivo, and some demonstrate considerable promise as antifungal agents. Therefore, to prevent the further loss of crops and resistance buildup, we propose to test the bio-fungicidal properties of lemongrass oil as an alternative to chemical fungicides in controlling plant pathogenic fungi. We tested the antifungal efficacy of lemongrass oil against Alternaria solani, Botrytis cinerea, Fusarium oxysporum, Pythium ultimum and Rhizoctonia solani, using a mycelial radial growth inhibition assay. The results of the study reveal that lemongrass oil has potent in vitro action against all these fungal species.

KEYWORDS: Plant Pathogens; Antifungal activity; Growth inhibition; Fungicide; Essential Oils.

\section{- Introduction}

Plant pathogens cause severe diseases and ultimately reduce the productivity and quality of crop and sometimes even destroy the entire crop. ${ }^{1}$ Plant pathogens can have terrible consequences if they are not prevented or suppressed.

Botrytis cinerea, commonly known as gray mold, affects over 200 crops such as grapes and strawberries resulting in monetary losses ranging from $\$ 10$ billion to over $\$ 100$ billion throughout the world. ${ }^{2}$ Alternaria solani is an air borne fungal sporulating ascomycetes known as early blight fungi. It causes a wide range of diseases mainly in tomatoes and potatoes that can result in up to $79 \%$ crop loss. ${ }^{3}$ Rbizoctonia solani, considered a soil borne pathogen, causes various plant diseases like root rot, damping off, wire stem, stem lesions, etc. ${ }^{4}$ Pythium ultimum is soil borne fungal plant pathogen which is the cause of damping off and root rot on many plants. Most plants are killed by Fusarium oxysporum, and by the time a plant shows any visible signs of infection, it is too late to combat, and the plant will die. ${ }^{5}$

The threat of antimicrobial resistance to chemicals and antibiotics has increased tremendously due to the excessive reliance on chemicals to control the plant pathogens either through growth inhibition or by killing plant pathogens. ${ }^{6}$ This threat has displayed the importance of using natural substances for controlling pathogens. Cymbopogon citratus, lemongrass, is an essential oil with a growing reputation due to its antimicrobial properties. ${ }^{7}$ Cymbopogon, commonly known as lemongrass or citronella, is a grassy plant found in tropical regions like South Asia, where people have utilized it for practices ranging from traditional medicine to food preservation. ${ }^{8}$ These plants are perennials that grow during the summer in moist and rich soils and can grow up to ten feet tall. They are well known for their aroma which has a similar smell to lemons. Cymbopogon is a genus of around 55 species with Cymbopogon citratus being primarily used for an essential oil which can be extracted from the leaf of the plant by steam distillation process. ${ }^{9,10}$
Lemongrass oil has been used for a variety of medicinal purposes such as pain relief, fevers, and gastrointestinal disorders for centuries. The effects of lemongrass on various pathogens have been investigated in several studies, and it is shown that it has antimicrobial, antibacterial, and antifungal properties. Studies have shown that lemongrass has demonstrated the ability to inhibit both plant and human pathogens. ${ }^{11}$

Citral is a key component when discussing the antimicrobial properties of lemongrass. Major compounds and its percentages present in lemongrass oil are Citral $\alpha-40.8 \%$, Citral $\beta-32 \%$, Nerol- 4.18\%, Geraniol-3.104\%, Citronellal-2.10\%, Terpinolene- $1.23 \%$ and Geranyl Acetate- $0.83 \%{ }^{12}$

The mode of action of lemongrass oil against foliar and post-harvest pathogens is not fully understood. Some studies have indicated that mycelium exposed to lemongrass oil go through morphological injury such as vesiculation, and cytoplasmic commotion besides folding of hyphae. ${ }^{13}$ The oil contains a high content of Citral composed of general and geranial isomers which may be the reason for their effective antifungal activity. Some of these active components present in essential oils can act on the pathogen directly or activate defense responses in host plants leading to a reduction in disease progress or can act directly through antagonism, which still requires further research. ${ }^{14}$

\section{Results and Discussion}

For a long time, medicinal plants and crude herbal products have been used in conventional medicines and household remedies. Not all herbal preparations have undergone scientific scrutiny. The antifungal activity of lemongrass oil against pathogenic fungi was investigated in this study, and the results indicate that lemongrass oil has substantial antifungal activity. These fungal species are associated with some common infections of plant species. The data shown in Figure 1 and Table 1 clearly indicates that all fungal strains tested were completely suppressed by lemongrass oil at $1.0 \%$ concentration. 
The inhibitory effect of lemongrass oil was proportional with concentrations used. Decreased effect of radial growth was observed when concentration was lowered to $0.5 \%, 0.25 \%$ and $0.1 \%$ respectively in all pathogens. At a concentration of $0.25 \%$, lemongrass oil was effective only against Alternaria solani and Fusarium oxysporum.

Table 1: Diameter of mean radial growth of various plant pathogens on agar plates after 5-7 days of incubation.

\begin{tabular}{|c|c|c|c|}
\hline $\begin{array}{c}\text { Plant } \\
\text { Pathogen }\end{array}$ & $\begin{array}{c}\text { Lemongrass oil } \\
\text { concentration } \\
\text { (\%) }\end{array}$ & $\begin{array}{l}\text { Mean radial } \\
\text { growth } \\
(\mathrm{mm})\end{array}$ & $\begin{array}{c}\text { Mean radial } \\
\text { growth inhibition } \\
\text { (\%) }\end{array}$ \\
\hline $\begin{array}{c}\text { Alternaria } \\
\text { solani }\end{array}$ & $\begin{array}{c}\text { Control } \\
\text { Soybean oil } \\
0.1 \\
0.25 \\
0.5 \\
1.0\end{array}$ & $\begin{array}{c}32 \\
34 \\
13 \\
12 \\
0 \\
0\end{array}$ & $\begin{array}{l}0.00 \\
0.00 \\
59.4 \\
62.5 \\
100 \\
100\end{array}$ \\
\hline $\begin{array}{l}\text { Botrytis } \\
\text { cinerea }\end{array}$ & $\begin{array}{c}\text { Control } \\
\text { Soybean oil } \\
0.10 \\
0.25 \\
0.5 \\
1.0\end{array}$ & $\begin{array}{c}35 \\
35 \\
35 \\
35 \\
10 \\
0\end{array}$ & $\begin{array}{l}0.00 \\
0.00 \\
0.00 \\
0.00 \\
71.4 \\
100\end{array}$ \\
\hline $\begin{array}{l}\text { Fusarium } \\
\text { oxysporum }\end{array}$ & $\begin{array}{c}\text { Control } \\
\text { Soybean oil } \\
0.1 \\
0.25 \\
0.5 \\
1.0\end{array}$ & $\begin{array}{c}35 \\
35 \\
15 \\
13 \\
0 \\
0\end{array}$ & $\begin{array}{l}0.00 \\
0.00 \\
57.1 \\
62.9 \\
100 \\
100\end{array}$ \\
\hline $\begin{array}{l}\text { Pythium } \\
\text { ultimum }\end{array}$ & $\begin{array}{c}\text { Control } \\
\text { Soybean oil } \\
0.10 \\
0.25 \\
0.5 \\
1.0\end{array}$ & $\begin{array}{c}35 \\
35 \\
35 \\
35 \\
17 \\
0\end{array}$ & $\begin{array}{l}0.00 \\
0.00 \\
0.00 \\
0.00 \\
51.4 \\
100\end{array}$ \\
\hline $\begin{array}{c}\text { Rhizoctonia } \\
\text { solani }\end{array}$ & $\begin{array}{c}\text { Control } \\
\text { Soybean oil } \\
0.10 \\
0.25 \\
0.5 \\
1.0\end{array}$ & $\begin{array}{c}35 \\
35 \\
35 \\
35 \\
30 \\
0\end{array}$ & $\begin{array}{l}0.00 \\
0.00 \\
0.00 \\
0.00 \\
14.3 \\
100\end{array}$ \\
\hline
\end{tabular}

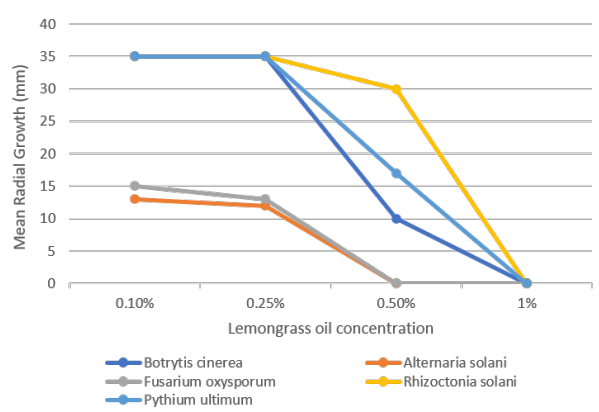

Figure 1: Mean radial growth of various fungal species at varying concentration of lemongrass oil. The graph shows a clear dose response among the concentrations tested.

Several essential oils have been tested for antimycotic activity in vivo and in vitro, with some showing promise as antifungal agents. Their mechanism of action focuses on the fungal cell membrane, destroying its structure and inducing cell death; spore germination, fungal proliferation, and cellular respiration are all inhibited; and membrane synthesis is prevented..$^{15}$ Due to their high volatility and lipophilicity, essential oils bind easily to the cell membrane and exert their biological impact. ${ }^{16}$ Antifungal susceptibility varies among fungal organisms, and numerous resistance mechanisms have antifungal sequestration in organelles like vacuoles, or chromosomal alterations, resulting in differential susceptibility of various fungal species to antimicrobial agents in this study.

The effect of lemongrass oil against Alternaria solani was studied using $1.0 \%$ concentration to determine the mycelial growth inhibition. Dose response studies were also conducted against Alternaria solani using various concentrations of lemongrass oil and results are shown in Figure 2. The results showed that lemongrass oil is highly effective against Alternaria solani, with a $100 \%$ reduction of growth observed at $1.0 \%$ and $0.5 \%$ followed $65 \%$ and $60 \%$ in $0.25 \%$ and $0.1 \%$ concentrations. These results clearly indicate that Alternaria solani is sensitive to lemongrass oil. The Minimum Inhibitory Concentration (MIC) value for Alternaria solani in this study was found to be $100 \mu \mathrm{L}$ per mL. Similar results have been reported in the previous studies of antimicrobial activities essential oils against Alternaria solani. ${ }^{17,18}$
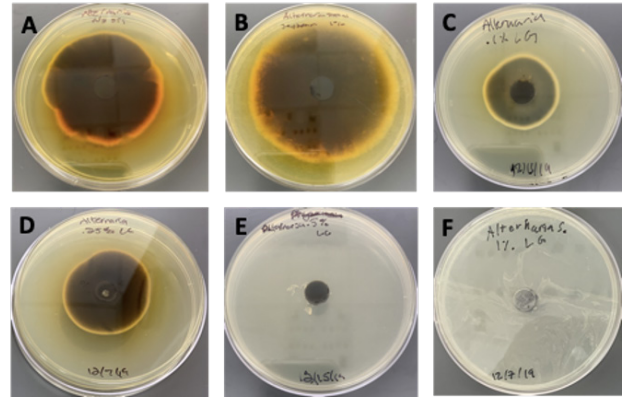

Figure 2: In vitro activity of lemongrass oil against Alternaria solani by radial growth inhibition. (A) Alternaria solani control (B) Alternaria solani with $1.0 \%$ soybean oil (C) Alternaria solani with $0.1 \%$ lemongrass oil (D) Alternaria solani with $0.25 \%$ lemongrass oil (E) Alternaria solani with $0.5 \%$ lemongrass oil (F) Alternaria solani with 1.0\% lemongrass oil. Lemongrass oil is highly effective against Alternaria solani, 100\% reduction of growth observed at $1.0 \%$ and $0.5 \%$ concentrations.

The antifungal activity of lemongrass oil was evaluated against Botrytis cinerea by measuring the radial growth on potato dextrose agar medium. Dose response studies were also conducted, and those results are shown in Figure 3. The lemongrass oil was found to be very effective and showed a $100 \%$ reduction of mycelial growth at $1.0 \%$ concentration. More than $70 \%$ reduction of growth was observed at $0.5 \%$ concentration and no effect observed at $0.25 \%$ and $0.1 \%$ concentrations respectively. These results indicate that lemongrass oil affect mycelial growth of Botrytis cinerea in a concentration dependent manner.

The effect of lemongrass oil against Fusarium oxysporum was studied using $0.1 \%$ to $1.0 \%$ concentrations to see the mycelial growth inhibition and the results are reported in Figure 4. The dose response study showed that lemongrass oil is highly effective against Fusarium oxysporum similar to Alternaria solani. $100 \%$ reduction of growth observed at $1.0 \%$ and $0.5 \%$, followed by around $62 \%$ and $57 \%$ in $0.25 \%$ and $0.1 \%$ concentrations. These results clearly indicate that Fusarium oxysporum is very sensitive to lemongrass oil. According to the results reported in Figure 5, the complete inhibition/reduction of mycelial growth of Pythium ultimum was observed at 1.0\% concentration and a more than $50 \%$ reduction at $0.5 \%$ 
concentrations. Full radial growth means no effect on radial growth was observed at $0.25 \%$ concentration of lemongrass oil on Pythium ultimum.
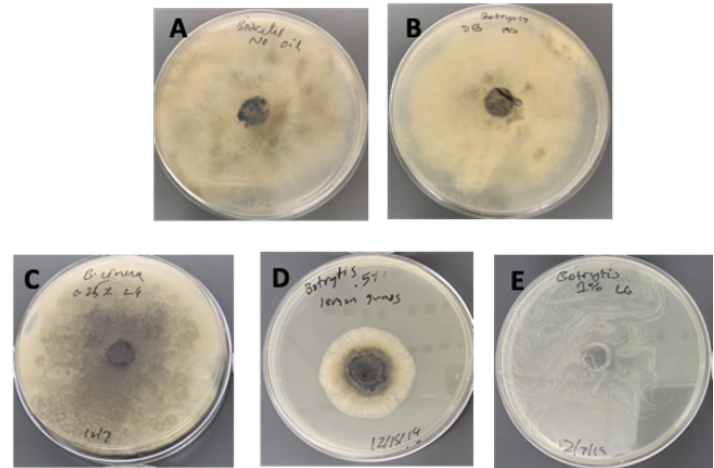

Figure 3: In vitro activity of lemongrass oil against Botrytis cinerea by radial growth inhibition. (A) Botrytis cinerea control (B) Botrytis cinerea with $1.0 \%$ soybean oil (C) Botrytis cinerea with 0.25\% lemongrass oil (D) Botrytis cinerea with $0.5 \%$ lemongrass oil (E) Botrytis cinerea with $1.0 \%$ lemongrass oil. The lemongrass oil was found to be very effective showed $100 \%$ reduction of mycelial growth at $1.0 \%$ concentration.
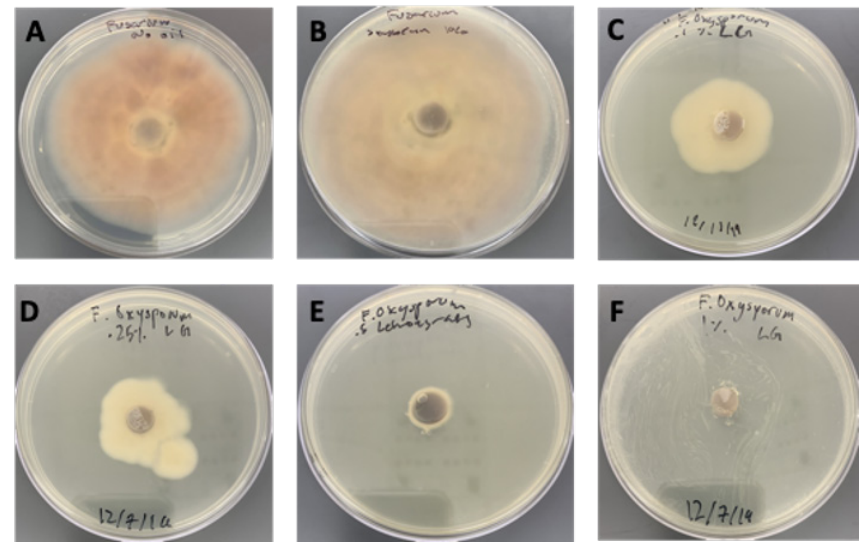

Figure 4: In vitro activity of Lemongrass oil against Fusarium oxysporum by radial growth inhibition. (A) Fusarium oxysporum control (B) Fusarium oxysporum with $1.0 \%$ soybean oil (C) Fusarium oxysporum with $0.1 \%$ lemongrass oil (D) Fusarium oxysporum with $0.25 \%$ lemongrass oil (E) Fusarium oxysporum with $0.5 \%$ lemongrass oil (F) Fusarium oxysporum with $1.0 \%$ lemongrass oil. The picture clearly shows a dose response with different concentrations of lemongrass oil.
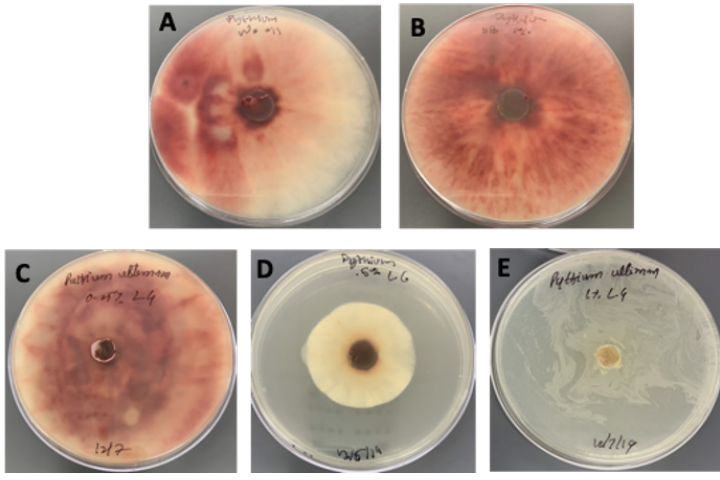

Figure 5: In vitro activity of Lemongrass oil against Pythium ultimum by radial growth inhibition. (A) Pythium ultimum control (B) Pythium ultimum with $1.0 \%$ soybean oil (C) Pythium ultimum with $0.25 \%$ lemongrass oil (D) Pytbium ultimum with $0.5 \%$ lemongrass oil (E) Pythium ultimum with $0.1 \%$ lemongrass oil. The picture clearly shows Pythium ultimum growth was completely inhibited at $1.0 \%$ concentration of lemongrass oil.
Similarly, the effect of lemongrass oil on mycelial growth of Rhizoctonia solani was studied and results shown in Figure 6. Rbizoctonia solani did not respond to lemongrass oil the same way as other pathogens. The complete inhibition of growth was observed at a $1.0 \%$ concentration of lemongrass oil, but not at lower doses. At a $0.5 \%$ concentration, there was only $15 \%$ mycelial growth reduction, while lemongrass oil displayed no effect at $0.25 \%$ and $0.1 \%$ concentrations.
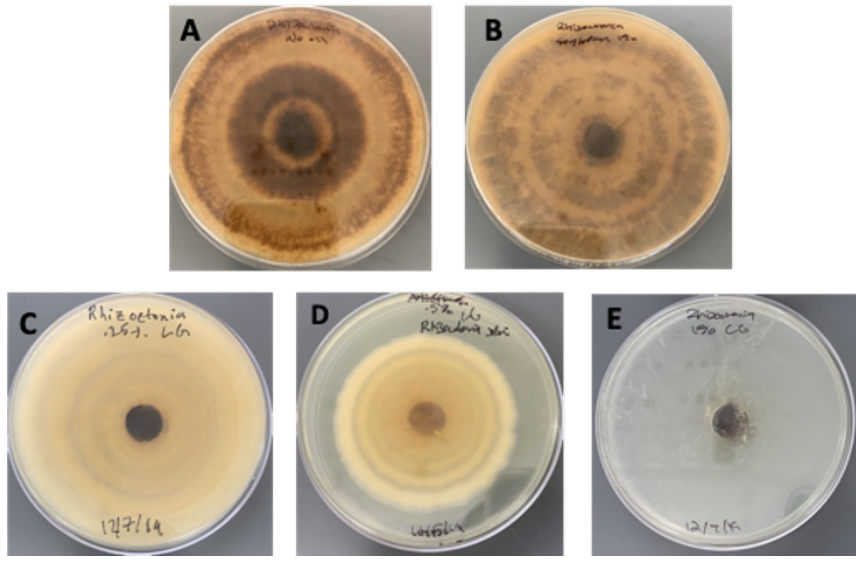

Figure 6: In vitro activity of lemongrass oil against Rhizoctonia solan $i$ by radial growth inhibition. (A) Rhizoctonia solani control (B) Rhizoctonia solani with $1.0 \%$ soybean oil (C) Rbizoctonia solani with $0.25 \%$ lemongrass oil (D) Rbizoctonia solani with $0.5 \%$ lemongrass oil (E) Rbizoctonia solani with $1.0 \%$ lemongrass oil. The picture shows Rhizoctonia solani growth was completed inhibited at $1 \%$ concentration of lemongrass oil.

We hypothesized that if lemongrass oil is used to control plant pathogenic fungi as an alternative to chemicals, then it will inhibit or minimize the mycelial or spore germination of the plant pathogens stated. The data showed that a $1.0 \%$ lemongrass oil concentration was able to inhibit all the pathogens tested completely. Dose-response studies were conducted to optimize the optimal concentration of lemongrass required to control and inhibit the growth of pathogens. These studies determined that a lower concentration of lemongrass oil increased the radial growth of all pathogens means decreased the effectiveness of pathogenicity. Thus, the findings of this study showed that lemongrass oil is an effective deterrent for plant pathogens alternative to chemical fungicides. However, lemongrass oil had greater radial growth inhibition in Alternaria solani and Fusarium oxysporum rather than Botrytis cinerea.

Citral and lemongrass oil had similar antifungal activity, which is consistent with previous research that related the effect to the occurrence of citral in lemongrass. ${ }^{19}$ Citral in lemongrass is a fungicidal agent, according to the literature, since it can form a charge transfer complex with a fungal electron donor, causing fungal death.

\section{- Conclusion}

The results of this investigation showed lemongrass oil has significant antimicrobial activity against plant pathogens. The fungi tested were Botrytis cinerea, Alternaria solani, Rhizoctonia solani, Fusarium oxysporum, and Pytbium ultimum. The aim of this investigation was to find whether lemongrass is effective against plant pathogens and could be used as a viable alternative candidate to chemical fungicides. Lemongrass oil was proven to have antimicrobial properties, and several researchers reported 
the use of medicinal purposes mainly for treating human diseases. Limited research was done against plant pathogens mainly against Pythium ultimum and Fusarium oxysporum.

Because of its antifungal efficacy, low cost, and low toxicity, these findings suggest that lemongrass oil could be used in pharmaceutical preparations for the control and treatment of fungal plant pathogens. Further research is required to test the unique antifungal properties of lemongrass oil and broadspectrum activity against other fungal and bacterial pathogens.

\section{Methods}

Pure natural steam-distilled lemongrass (Cymbopogon citratus) oil was obtained from SVA Organics. Plant Pathogen namely Botrytis cinerea Alternaria, solani, Rhizoctonia solani, Pythium ultimum and Fusarium oxysporum were obtained from American Type Culture Collection (ATCC). Potato Dextrose Agar (PDA) was prepared using premix agar medium obtained from Carolina Biosciences. PDA plates with lemongrass oil $(1 \%, 0.5,0.25 \%, 0.1 \%)$ concentrations were made following the standard protocol, autoclaving the medium, cool down to $50^{\circ} \mathrm{C}$ and make plates by transferring $20 \mathrm{ml}$ to each plate manually. ${ }^{20}$ Plates of various concentration for experimental and control groups were labeled.

Making of PDA plates with various lemongrass oil (1\%, 0.5 , $0.25 \%, 0.1 \%)$ concentrations:

We added $500 \mathrm{ml}$ of tap water to 20 grams of free mixed, commercially available potato dextrose agar powder into a 1.0 Liter flask and mixed and stirred with a magnetic bar. Then $5.0 \mathrm{~mL}$ of lemongrass oil was added into the medium before autoclaving to create $1.0 \%$ lemongrass oil concentration. The media was then autoclaved at $121^{\circ} \mathrm{C}(15 \mathrm{psi})$ for 15 minutes and transferred to water bath at $50^{\circ} \mathrm{C}$ so the media did not solidify. The flask from the water bath was taken out and moved to a biosafety cabinet. $20 \mathrm{ml}$ of the medium was dispensed into each petri plate and plates were allowed to solidify overnight completely. The same procedure was used to make $0.5 \%, 0.25 \%$ and $0.1 \%$ concentration plates. For controls, the same media preparation procedure was used as mentioned above with/ without adding soybean oil to the medium.

\section{Antifungal Assay (Radial Growth inhibition):}

The antagonistic activity of lemongrass oil on radial growth of the test organisms was measured by placing a mycelial agar plug on the center of the PDA plates with various concentrations of lemongrass oil. The plate containing only PDA medium without lemongrass/soybean oil used as pathogen control and a plate containing $1.0 \%$ soybean oil was used as a negative control. Three plates of each concentration for each pathogen were used. Each experiment was performed in triplicates.

To transfer the mycelial plugs from plate to plate, a cork borer and forceps were used to extract an agar plug from the middle of each potato dextrose agar plate. The same step was repeated to extract agar plugs for all the plates. Then, a slightly larger cork borer was used to cut the mycelial plug from the pathogenic plate. All plates were sealed with parafilm and incubated in a biological incubator at $28^{\circ} \mathrm{C}$. After 5-7 days, the radial growth of each of the pathogens was measured by calculating the colony diameter on each replicate. Photographs were taken using camera and the radial growth inhibition was assessed by computing the width of the soybean oil and no oil controls on a regular ruler. All plates were disposed of in a biohazard autoclave bag and autoclaved at $121^{\circ} \mathrm{C}$ for $30-60$ minutes prior to disposal.

\section{Acknowledgements}

We thank American Type Culture Collection (ATCC) and Carolina Biosciences for providing cultures and media plates. We sincerely thank Mrs. Christina Palffy, Adlai E Stevenson High School, IL for her continuous assistance, critical review of this manuscript, and feedback throughout the study. We also thank our parents for their continuous moral support, helpfulness, and encouragement of our ideas during these studies.

\section{References}

1. Lamichhane, J. R.; Venturi, V. Synergisms between Microbial Pathogens in Plant Disease Complexes: A Growing Trend. Front. Plant Sci. 2015, 6, 385.

2. Williamson, B.; Tudsynski, B.; Tudzynski, P.; Van Kan, J 1. Botrytis cinerea: the cause of grey mould disease. Molecular Plant Pathology. 2007, 8 (5), 561-580.

3. Adhikari, P.; Oh, Y.; Panthee, D. R. Current Status of Early Blight Resistance in Tomato: An Update. International Journal of Molecular Science. 2017, 18 (10).

4. Ralph Baker and C. A. Martinson. Epidemiology of Diseases Caused by Rhizoctonia solani, University of California Press, Berkeley. 1970, pp 172-188.

5. Arie Tsutomu. Fusarium diseases of cultivated plants, control, diagnosis, and molecular and genetic studies. Journal of Pesticidal Science. 2019, 44 (4), 275-281.

6. Chandra, H.; Bishnoi, P.; Yadav, A.; Patni, B.; Mishra, A. P.; Nautiyal, A. R. Antimicrobial Resistance and the Alternative Resources with Special Emphasis on Plant-Based Antimicrobials—a Review. Plants. 2017, 6 (2), 16.

7. De Silva, B. C. J.; Jung, W. G.; Hossain, S.; Wimalasena, S.; Pathirana, H.; Heo, G J. Antimicrobial Property of Lemongrass (Cymbopogon citratus) oil against Pathogenic Bacteria Isolated from Pet Turtles. Lab. Anim. Res. 2017, 33 (2), 84-91.

8. Ekpenyong, Ch.E., Akpan, E.E. Use of Cymbopogon citratus essential oil in food preservation: Recent advances and future perspectives. Critical Reviews in Food Science and Nutrition, 2017, 57(12), 2541-2559.

9. Baruah, J.; Gogoi, B.; Das, K.; Ahmed, N. M.; Sarmah, D. K.; Lal, M.; Bhau, B. S. Genetic Diversity Study amongst Cymbopogon species from NE-India Using RAPD and ISSR Markers. Ind. Crops Prod. 2017, 95, 235-243

10.Schaneberg, B.T., Khan, I.A. Comparison of extraction methods for marker compounds in the essential oil of lemongrass by GC. Journal of Agricultural and Food Chemistry. 2002, 50 (6), 13451349.

11.Balakrishnan, B.; Paramasivam, S.; Arulkumar, A. Evaluation of the Lemongrass Plant (Cymbopogon Citratus) Extracted in Different Solvents for Antioxidant and Antibacterial Activity against Human Pathogens. Asian Pacific J. Trop. Dis. 2014, 4, S134-S139.

12.Tyagi, A. K.; Gottardi, D.; Malik, A.; Guerzoni, M. E. Chemical Composition, in vitro Anti-Yeast Activity and Fruit Juice Preservation Potential of Lemongrass oil. LWT-Food Sci. Technol. 2014, 57 (2), 731-737.

13.Tak, J. H.; Isman, M. B. Metabolism of Citral, the Major Constituent of Lemongrass oil, in the Cabbage Looper, 
Trichoplusia $\mathrm{Ni}$, and Effects of Enzyme Inhibitors on Toxicity and

Metabolism. Pestic. Biochem. Physiol. 2016, 133, 20-25.

14.Mbili, N. C.; Laing, M. D.; Yobo, K. S. Integrated Control of

Penicillium expansum and Botrytis cinerea of Apples Using

Potassium Silicate, Yeast Antagonists and YieldPlus ${ }^{\circledR}$. In XXX

International Horticultural Congress IHC2018: II International

Symposium on Innovative Plant Protection in Horticulture.

2018 1269, pp 75-80.

15.Kryvtsova, M. V.; Kohuch, T. T.; Salamon, I.; Spivak, M.J.

Antimicrobial Activity of Some Essential Oils on Candida Genus Clinical Isolates. Мікробіологічний журнал. 2018, Vol 80 (4), $3-12$.

16.Chouhan, S.; Sharma, K.; Guleria, S. Antimicrobial Activity of Some Essential Oils-Present Status and Future Perspectives. Medicines (Basel). 2017 Sep; 4(3): 58.

17.Hassanein, R. A.; Salem, E. A.; Zahran, A. A. Efficacy of Coupling Gamma Irradiation with Calcium Chloride and Lemongrass oil in Maintaining Guava Fruit Quality and Inhibiting Fungal Growth during Cold Storage. Folia Hortic. 2018, 30 (1), 67-78.

18.Ragupathi, K. P.; Renganayaki, P. R.; Sundareswaran, S.; Kumar, S. M.; Kamalakannan, A. Evaluation of Essential Oils against Early Blight (Alternaria solani) of Tomato. Int. Res. J. Pure Appl. Chem. 2020, 164-169.

19.Gupta, A. K.; Ganjewala, D. A Study on Biosynthesis of "Citral" in Lemongrass (C. Flexuosus) Cv. Suvarna. Acta Physiol. Plant. 2015, 37 (11), 1-8.

20.Erin R. Sanders. Aseptic Laboratory Techniques: Plating Methods. JVis Exp. 2012; (63): 3064.

\section{Author}

Yashwanth Gangavarapu is a rising senior student studying at Adlai E. Stevenson High School, Lincolnshire, IL, USA. He is interested in research, designing, and understanding basic concepts of science, especially in artificial intelligence and machine learning, and applying those technologies in plant and human diseases. He plans to pursue his undergraduate degree either in electrical, biomedical, or aeronautical engineering. His other interests include lacrosse, soccer, and volunteering to teach young kids.

Suhas Palwai is a rising senior student studying at Adlai E. Stevenson High School, Lincolnshire, IL. He is interested in pursuing Computer Science. Suhas enjoys writing code, exploring techniques, and learning new principles to write simpler and efficient code. His other interests include fencing, playing chess, baking, and keeping himself fit. 